\title{
Editorial: Advancing Teaching Innovation and Research Excellence in Higher Education
}

\author{
Rubby Dhunpath \\ Nyna Amin \\ Langa Khumalo
}

The theme of this special edition derives from the $10^{\text {th }}$ Annual Teaching and Learning Conference, which focussed on advancing teaching innovation and research excellence in higher education. We were privileged to have hosted one of the world's most eminent scholars of the scholarship of teaching and learning (SoTL), Lee Shuman. Offering profound insights into the intersection of research and practice within the landscape of the Academy, Shulman asked: "What is "evidence" for the improvement of teaching and learning in an unscripted and highly contextualized world?' He argued that 'whether describing good medical practice, educational design, or management in business, experts insist that judgments and decisions are evidence-based.'

Setting up for scrutiny the distinctions amongst evidence, conjecture, speculation, anecdote or fantasy, he challenged us to consider how we use, acquire, create or defend what counts as 'evidence' in our pedagogies and our designs. The question of evidence is particularly relevant in the context of challenging the archetypical university teacher who is expected to conduct research, teach, and perform community service. As teaching rises beyond the status of the 'poor cousin' of research, academics increasingly have an obligation to make public the 'evidence' that characterises teaching excellence. Performance metrics no longer suffice as indicators of excellence, nor do selfstudy narratives.

As Hutchings, Huber and Ciccone implored in SoTL Reconsidered (2011), we have an obligation to move scholarship to the epicentre of individual and institutional work by researching teaching, learning, and professional development, while simultaneously recognising and rewarding 
pedagogical work. Caught up in episodic projects or interventions, we are a long way from that ideal where SoTL is fully inscribed into our institutional commitments to student learning and progression. A more enduring, albeit ambitious, approach to embed a deep SoTL, is to adopt a systemic approach to development. While SoTL is typically associated with systematic reflection and investigation of praxis, it is perhaps worth considering the ways its underlying principles can serve as catalysts for sector-wide development and change, particularly in contexts where institutions battle to shed historicized identities.

One of the main ingredients for sector-wide development is scholars' willingness to embrace the value of interdisciplinary work alongside conventional modes of disciplinary enquiry. As the value of prosaic notions of conventional enquiry is placed under scrutiny, the raison d'être of higher education is being challenged, notably by students, who are questioning the relevance of higher education curricula. An enduring condition inhibiting collaboration is our adherence to essentialised disciplinary and cultural identities. Escalated calls for academics to embrace interdisciplinarity (as a hedge against obsolescence) has generated research which integrates the social and natural sciences and has brought together researchers to collaborate across disciplinary, epistemological and methodological boundaries.

Suspending our exclusive disciplinary preoccupations opens up possibilities for a scholarship that is reflective of the post-colonial condition. Repeated failures over the years to address perennial problems in higher education related to curriculum, institutional cultures, governance and financing, behoves us to concede that conventional modes of enquiry no longer effectively serve their intended purposes; it calls, instead, for radical shifts from individualistic to collaborative approaches. The pursuit of participant parity requires us to feel comfortable with making public our curiosity about each other's work, and in the process, to share in the common values, interests and beliefs that emerge through engagement in inter-institutional projects and sharing of research.

\section{A Policy Framework to Support SoTL}

Is it possible to create spaces and enabling transitions for engagement in SoTL and can policy provide a framework for action? This is the question Joyce 
Nsibande probes in her similarly titled article. She contends that a major challenge is how to move SoTL from being an option for interested academics to a culture embedded in the way higher education institutions normalise teaching and learning. She approaches this challenge through the lenses of policy aimed at encouraging the uptake of SoTL. She argues that the practices foregrounded in the policy statements create spaces to support academics' transitions to engage in SoTL. However, for this to happen, a clear institutional strategy is required to support change at all levels. The strategy, she contends, should provide support and guidance for the uptake of SoTL at individual, faculty, and institutional levels. She demonstrates how policy directives, practices and institutional contexts can create counterproductive environments and can lead to a departure from the core intentions of the policy. For example, instead of engaging in the instrumental use of the evaluation results (to inform inquiry), there could be a default to legitimisation use (to justify teaching practice and demonstrate performance for rewards) or non-use. Both the 'legitimisation use' and 'non-use' are a result of what is generally valued in institutions and, to some extent, show a lack of the support needed for change. It cannot summarily be assumed that academic staff will have the capacity to adopt the required ways of working to engage in SoTL without support and an enabling institutional culture.

\section{Individual Agency to Inform SoTL}

SoTL, we can agree, is about individual agency, responsibility for conducting evaluations and using the evaluation results to inform engagement of SoTL. This is possible when support is provided to develop capacity so that academics can make appropriate decisions about teaching and learning and are imbued with the confidence to select the tools that will elicit relevant feedback. Rewarding SoTL in ways other than monetary means can help ensure that motivation is propelled by academic values rather than personal gains.

Appraising the inherent value and personal gain to be derived from migrating to SoTL is perhaps an unreasonable expectation for the academic who has to negotiate competing demands on her time. Are there potential leverage points for academic staff to be ushered into SoTL? Noting the potentially alienating epistemic shifts necessitated by designing and conducting SoTL research, the notion of threshold concepts is particularly 
useful in facilitating the shift in structure, culture and agency both at the level of the individual and at the institutional level. Threshold concepts are defined by Meyer and Land (2003) as core ideas that are cognitively challenging for learners, who struggle to comprehend it, but once grasped, it radically transforms access to learning. For Meyer and Land (2003: 14),

A threshold concept can be considered as akin to a portal, opening up a new and previously inaccessible way of thinking about something. It represents a transformed way of understanding, or interpreting, or viewing something without which the learner cannot progress.

\section{Threshold Concepts for Deep Learning}

At the level of the subject or discipline, threshold concepts offer the potential for deep learning. This is demonstrated by the work of Davis and Maistry who explore 'involvement' and 'fun' as potential for deep learning. Billed as unusual suspects in a higher education economics programme, they argue that games have much potential as pedagogical tools and key catalysts to stimulate learning. They note that the students firmly placed 'involvement and fun' at the core of the learning process. The resultant deeper learning of economic concepts they argue, has implications as there needs to be a re-evaluation of the terms 'involvement' and 'fun' with respect to the enhanced learning which students experienced in the classroom. Their findings highlight the potential of economic games for student learning in a re-imagined teaching and learning space in teaching and learning contexts dominated by the traditional 'chalk and talk' lecture method. Considering the demand for graduates to have the ability to problem-solve, possess critical thinking skills and be able to collaborate with others, the higher education environment has to change from cognitive loading to 'cognitive apprenticeship'. Embedding games into the curriculum, can engender change as they create autonomy-supported learning environments that bring together the emotional and cognitive aspects of learning (total involvement) while at the same time binding the students together in community of practice which 'could move our system of education beyond the traditional disciplines, and towards a new model of meaningful learning' cognitive apprenticeship. This shift in focus from outcomes-based learning (objects and facts) to the creation of learning spaces that facilitate deeper conceptual understanding (activity) is a desirable outcome. 


\section{Promoting Criterion-referenced Expert Learning}

Meaningful learning takes on a different complexion in Health Sciences departments. Doctors and radiologists in particular, are critical for good health care provisioning - but scarce resources with insufficient numbers of specialists to train the numbers of specialist practitioners required in the country threatens to scupper the efforts. The result is that actual teaching in clinical settings is sporadic. The challenges faced by an overstretched health care system and lack of resources is compounded by the loss of qualified health care workers to migration. Thus, medical specialists take on the tasks of teaching (without teaching certification) to produce the next generation of specialists. Under these circumstances, the novice is often charged with her/his own learning and radiological competence is, as a consequence, experiencebased, intangible and tacit. Self-directed learning is laudable but in the medical field it can be risky.

In a position paper entitled 'Towards a realistic description of competence for new radiology graduates in South Africa', Govind and Amin propose a rearticulated version of the Dreyfus and Dreyfus approach for clarifying competencies that new radiology specialists should acquire. The authors argue that in the absence of criterion-referenced descriptions, competence is an empty crucible and is thus susceptible to a variety of interpretations, manifestations and practices which could lead to unintended consequences. The re-articulated model, they contend, is useful to distinguish expert from novice radiological competencies. The proposed model is incomplete with only a segment on perceptive skill offered for the purposes of beginning a conversation about radiological competence. The push for explicit criteria is critical as it means that novices who work without supervision can use it to guide their own development and growth. The article demonstrates the potential value of interdisciplinary undertakings for teaching complex competencies to qualified interns as they move from novice to expert levels of professionalism.

\section{Increasing the Currency for African Pedagogy and Epistemology}

Debates around competence are invariably linked to issues of legitimacy and profane epistemologies. Codified knowledges secure the status of 'legitimate', 
while knowledge systems that have not developed parallel technologies enjoy marginal status. The notion of a new African pedagogy and epistemology is gaining currency as scholars explore African modes of knowledge exploration that are experiential rather than abstract; communal and cooperative rather than competitive; and produced in the context of relevant application rather than an esoteric indulgence. An African epistemology is said to re-centre the value of indigenous languages, spirituality, narratives, symbolic imagery, the supernatural, ritual, myths and social traditions as legitimate teaching and learning tools and outcomes. Scholars who traverse disciplinary borders to investigate the elusiveness of African scholarship are applauded, particularly since such intellectual work has hazards like reproducing a narrow parochial conception that is essentialist on the one hand but a broad, cosmopolitan and, arguably, more scientifically informed conception on the other. The intellectualisation of African languages is, undoubtedly, central to the emancipatory agenda.

In Keet and Khumalo's article, 'Evaluation of the effects of a spellchecker on the intellectualisation of isiZulu', we are given insights into a bilingual language policy and plan in a higher education institution, which recognises English and isiZulu as official languages. The strategy as articulated in the language policy and plan, aggressively promotes the intellectualisation of isiZulu as an effective process to advance indigenous, under-resourced African languages as vehicles for innovation, science, and technology research in higher education and training institutions. The development of human language technologies (HLTs) which includes an isiZulu spellchecker, established on an organic isiZulu National Corpus, demonstrates that the spellchecker has had a positive impact on the work of target end-users, who also perceive it as an enabler for the intellectualisation of isiZulu. The technology, it is argued, is proving to be generative and democratic as the spellchecker accelerates the addition of new words to the isiZulu lexicon. Through an evaluation using the System Usability Scale of both the architecture and use of the isiZulu spellchecker, the authors contend that it has a positive effect on the intellectualisation of isiZulu. Perceived by the target audience as generative of interest in further functionalities afforded by the technology, the isiZulu spellchecker's 'add-on dictionary' feature is proving useful from a 'computational viewpoint as well as a linguistic one, to examine emerging words and orthography'. The authors conclude that new words added to the lexicon are testimony to the claim that the intellectualisation of the lang- 
uage is taking root as the tool is being actively used in technical spaces such as administration work (formal language), translation work and editing.

\section{Disrupting Hegemonic Articulations in Higher Education Teaching and Learning}

Recent upheavals in higher education suggest that there is an awareness that the status quo cannot be maintained, that change is crucial and that higher education needs to engage in a renewal process that puts Africa and its inhabitants at the centre without reducing change to a narrow Africanism. The debates, discussions and tensions of a decolonial curriculum or qualification galvanised by social, political and economic demands for relevant education, requires not only action; it obligates a rethinking, a reviewing, and reframing of hegemonic articulations and practices in higher education. A number of articles speak directly to the destabilisation of existing hegemonies.

The article by Leibowitz, 'Power, Knowledge and Learning: Dehegemonising Colonial Knowledge' signals efforts to intellectualise nonwestern modes of knowledge, thinking and doing. In this authoritative piece, Leibowitz unveils the toxicities of colonial knowledge, which has occupied, over centuries, a lofty posture and purview of what counts and what is discarded. Dismantling the power of colonial knowledge, she argues, consists of firstly, acknowledging the detrimental aspects of current codes of knowledge, followed by dehegemonic practices while factoring in the limitations posed by these efforts. It is common knowledge that the decolonisation project cannot be eschewed, eliminated or ignored so we are well advised to consider carefully the arguments proffered by Leibowitz.

\section{Large State Hegemony of Institutional Operations in a Small Island State}

'Curriculum Responsiveness in Teacher Professional Development Programmes' by Ankiah-Gangadeen and Pascal explains how institutions in the Island of Mauritius respond to a peculiar set of contextual conditions. Speaking from across the Indian Ocean, they argue that a small island state like Mauritius borrows and models its programmes from large non-island states even when it defies practical rationality. It seems that the hegemony of 
institutional operations in Mauritius are dominated by agendas of large states that are received as normal. For example, with a potential student population of under 50000 , the proliferation of institutions and duplication of programmes is unusual, and inexplicable, unless one detects a deeper economic logic driving the entire enterprise, that is the commodification of knowledge contemporaneous with a reduction in state funding.

\section{Challenging the Domination of Low Cognitive Demand Assessment Tasks}

'Assessment and Cognitive Demand in Higher Education Accounting Textbooks' by Arek-Bawa and Dhunpath unveils the hegemony of low cognitive demand assessment tasks in accounting textbooks. The South African Career Junction Index of 2016 shows that jobs for accountants are a growing demand, a pattern discernible in Nigeria as well. This places an obligation on higher education to produce accountants who are technically competent and intellectually skilled. Noting that textbooks are a mainstay of higher education curriculum, the authors examined the nature of assessments tasks to gauge the quality of learning. Their findings are worrying: the assessment tasks in selected text books require low cognitive demand by students. In other words, it tests items that are unchallenging and give a false sense of competency. The authors suggest that alternative measures of assessment be introduced so that higher order thinking and learning outcomes can be assured.

\section{Enabling Teaching and Learning through Multimodal Approaches}

The study by Rodrigues evaluates the impact of a multimodal approach to provide assisted learning specifically to EAL students. Using a blog where students can operate in an unthreatening learning environment in the language and mode of their choice, the study demonstrates how students' understanding of threshold concepts were deepened. The study demonstrates that using various modes and mediums provides all participants with an enabling teaching and learning environment. The blog with its variety of communication modes provides a learning space, where students assimilate their diverse semiotic 
resources and knowledge sources with the language of Mechanics. It is clear from the study that a multimodal approach which introduces mediating texts through translanguaging offers novel pedagogies in the teaching and learning spaces by disrupting the use of English.

By highlighting multisensory perception through various modes, the end user is enabled to transcend the English language paper-based text to negotiate meaning. This study provides evidence that Mechanics students gain access to complex applied sciences concepts by transforming paper-based information into signs, objects, sound, images, and emergent mental representations. A developed multisensory perception therefore provides a scaffold to make the correct interpretation when words or concepts are foreign or strange. It can be argued that South African Higher Education is increasingly embracing the imperative of transmuting African languages to be the kernel of the academy. The introduction of these languages is motivated by pedagogic reasons to facilitate knowledge access and student success as articulated in the 1994 UNESCO World Conference framework of action. The frameworks encourage the recognition and response 'to the diverse needs of their students, accommodating both different styles of learning and ensuring quality education to all through appropriate curricula, organizational arrangements, teaching strategies, resource use and partnerships with their communities'. The language papers argue persuasively for the cultivation of African languages so that they become languages of all academic activity in order to eliminate problems of language being as an impediment to access and success.

\section{Disrupting English Hegemony in Higher Education}

The imperative to challenge the use of certain hegemonic languages as established praxis in the African academy is articulated in three papers. Mchombo argues that education in Africa has failed to locate language as the main reason for the high attrition rate in the education system. Language proficiency plays a central role in attaining a holistic education. He contends that hitherto, the operative assumption has been that African education is delivered in ex-colonial languages due to their centrality to math, science, and technology. His article focuses on the fallacies behind such assumptions and he argues that the retention and entrenchment of European languages as languages of instruction serve to solidify the 'conceptual-cum-linguistic incarceration' of African education. 
Persistent criticism of education in Africa revolves around its resistance to 'decolonisation'. It excludes Africans' concerns and worldviews and prevents research being conducted from an African perspective for Africans' own purposes. It is Mchombo's conclusion that African education should desist from insulating foreign languages, cultures, and knowledge systems from African values and cultures in schools.

Prah argues very strongly in his article The Intellectualization of African Languages for Higher Education' that Africa can make more progress if African languages are situated at the centre of the education system. Language is at the centre of driving any meaningful transformation in society. There is little hope of developmental progress without the intellectualized use of African languages in higher education and this realization is beginning to grow and resonate across the continent and beyond in various contexts and on differing platforms. Ultimately, African languages as intellectualized media are culturally the single most important instrument for the empowerment of mass society and the optimization of human capital in Africa.

Higher educational institutions, because of their heights in the educational structures of society, must take the lead in enabling the intellectualization of African languages. Departments providing instruments and materials need to be established. Departments and dedicated specialists for these purposes need to be created. South Africa, as the best resourced country in terms of infrastructure, is most suitably placed to take a lead in this endeavour. There is also the incomparable advantage of Afrikaans, which offers a technical example to other African languages, of how to transmute African languages to become fully intellectualised languages capable of articulating the full rigors of science and mathematics. African languages, it seems, must disrupt the hegemony of English in the academy if they are to be developed as scientific languages.

\section{References}

Hutchings, P., M.T. Huber \& M. Ciccone 2011. The Scholarship of Teaching and Learning Reconsidered. San Francisco: Jossey Bass.

Meyer, J.H.F. \& R. Land 2003. Threshold Concepts and Troublesome Knowledge: Linkages to Ways of Thinking and Practising within the Disciplines. In Rust, C. (ed.): Enhancing Teaching and Learning in 
Undergraduate Courses: Occasional Report 4. Edinburgh: School of Education, University of Edinburgh.

UNESCO 1994. The Salamanca Statement and Framework on Special Needs Education. Paris: UNESCO.

Rubby Dhunpath

Director of Teaching and Learning University of KwaZulu-Natal dhunpath@ukzn.ac.za

Nyna Amin School of Education University of KwaZulu-Natal amin@ukzn.ac.za

Langa Khumalo Linguistics Program University of KwaZulu-Natal khumalol@ukzn.ac.za 